\title{
Shape memory epoxy vitrimers based on waste frying sunflower oil
}

\author{
Simon Nicolas ${ }^{a, *}$, Tiphaine Richard ${ }^{a}$, Juliette Dourdana, Loïc Lemiègre ${ }^{a}$, Jean-Luc Audic ${ }^{a, *}$ \\ *Corresponding author: simon.nicolas@ensc-rennes.fr, jean-luc.audic@univ-rennes1.fr \\ ${ }^{a}$ Univ Rennes, Ecole Nationale Supérieure de Chimie de Rennes, CNRS, ISCR - 6226, F-35000 Rennes, France
}

\begin{abstract}
Thermoset polyesters are prepared from epoxidized waste frying sunflower oil (ESO), commercially available epoxy compounds and glutaric acid. Influence of the nature and concentration of bi- and trifunctionnal epoxy compounds on mechanical properties is studied. Static and dynamic mechanical tests are performed. The molar amount of commercial epoxy compounds used ranges from $20 \%$ to $80 \%$ regarding the molar amount of ESO. It enables to obtain thermosetting polyesters with glass transition temperatures ranging from $6^{\circ} \mathrm{C}$ to $102^{\circ} \mathrm{C}$, as well as storage modulus ranging from $8 \mathrm{GPa}$ to $14 \mathrm{GPa} .40 \%$ of trifunctional epoxy compound and $60 \%$ of commercial epoxy compound are found to be the best compromises between bio-based content and mechanical properties. Furthermore, shape memory and vitrimer behavior of those epoxy-acid based networks with $60 \%$ of commercial epoxy compounds are evaluated both qualitatively and quantitatively by cyclic thermo-mechanical and stress relaxation tests. Excellent shape memory behavior with fixity ratios above $94 \%$ and recovery ratios above $98 \%$ is demonstrated. A transesterification catalyst is needed to obtain good vitrimer behavior. Overall, thanks to the previously mentioned properties of those partially biobased thermosets polyesters, industrial applications such as protective coatings, foams and temperature-memory polymer actuators might be considered.
\end{abstract}

\section{Introduction}

Nowadays bio-based materials are increasingly used because of environmental concerns[1,2], especially regarding renewability. Vegetable oils (VO), composed mainly of triesters of glycerol and fatty acids, are interesting renewable raw materials for several reasons: abundance, low price and active sites for chemical modifications[3]. Main active sites are : double bonds, hydroxyls, allylics carbons, esters and alpha carbon to the ester group. Materials such as alkyd resins, polyurethanes, polyamides, vinyl and epoxy resins can be obtain through chemical reactions on those active sites[4]. Alkyd resin refers to polyesters modified with fatty acids[5]. They are prepared by the condensation polymerization of polyalcohols, polybasic acids and fatty acids usually derived form VO. They are widely used in the paint and coating industry. Polyurethanes are synthetized by polymerization reactions between isocyanates and polyols. A wide variety of bio-polyol can be obtained from vegetable oils throught epoxidation/oxirane ring-opening, ozonolysis/reduction, hydroformylation/hydrogenation, transesterification/amidation, metathesis and thiol-ene reaction. It is also possible to synthesize non-isocyanate polyurethane (NIPU) by a reaction between polycyclocarbonates and polyamines which can be obtained from VO[6]. Polyamides are made from

\section{ACCEPTED MANUSCRIPT}


the polycondensation of dicarboxylic acids and diamines or by the ring-opening polymerization of lactams. All of those monomers can be derived from vegetables oils[7]. A famous example is the use of ricinoleic acid derived from castor oil to produce PA 11. Vinyl resins can also be obtained from VO. Apart from tung oil there is no other vegetable oil that can undergo free radical or cationic polymerization. Therefore, vinyl moieties must be introduced prior to polymerization. It is done by the incorporation of either acrylate or methacrylate or by the isomerization of non-conjugated double bonds in fatty acid into conjugated counterparts[8]. Double bonds in fatty acid chains can also be transform in epoxy groups through chemical or enzymatic routes. Epoxidation of VO with peracids to form epoxidized vegetable oil (EVO) is one of the most used. EVO can be directly polymerized or cured with severals types of curing agents like diamines, dicarboxylic acids or anhydrides. EVO are used in many applications such as plasticizer for poly(vinyl chloride)[9,10] or polyhydroxyalkanoate[11], coatings[12] or bio-based bioresorbable polyesters[13]. Regarding biodegrable polymers, epoxidized soybean oil has been used to prepare a novel hybrid quaternized soybean oil and poly (L-lactide) based polymer[14] and to modify poly(vinyl alcohol) via ring-opening polymerization[15]. Another Vo used for epoxidation is sunflower oil. Indeed, sunflower oil is one of the most produced VO and it is mainly composed of linoleic acid $(53,8 \%)[16]$ which possesses two insaturations. The production of vegetable oils is mainly intended for the food[17] and biodiesel[18] sectors. In order not to hinder those market shares, the raw material used in the present research work is waste frying sunflower oil. Recycled frying oil is environmentally friendly[19] and economic[20]. Sunflower oil is mainly composed of oleic and linoleic chains [21] which possess one and two unsaturations respectively, potentially epoxidizable. By further reacting a dicarboxylic acid with an EVO it is possible to crosslink this material by creating new ester bonds to finally obtain thermoset polyesters. Previous work[22] showed that these polyesters have glass transition temperature below ambient temperature and exhibit relatively poor mechanical properties, which reduce their end-use applications. In order to enhance mechanical properties, blends of commercially available bi- and tri- epoxides (3,4-epoxycyclohexylmethyl-3', $4^{\prime}$ epoxycyclohexanecarboxylate; bisphenol A diglycidyl ether; tris(4-hydroxyphenyl)methane triglycidyl ether) with epoxidized waste frying sunflower oil (ESO) and glutaric acid were prepared. Influence of the amount of commercially available epoxide on tensile, hardness and dynamical mechanical properties of the resulting thermoset polyesters was studied. Previous works with blends of DGEBA and EVO were done to study the influence of the percentage of EVO on mechanical and thermal properties of the synthesized polyethers $[23,24]$. Increased amount of DGEBA increased thermal stabilities as well as the tensile stress of the blends. Besides, previous works with blends of DGEBA with EVO and anhydrides as curing agents were done to studied curing kinetics[25], thermal and mechanical properties[26] of the thermosetting polyesters. It was found that a combination of DGEBA with $40 \mathrm{wt}$ $\%$ epoxidized soybean oil resulted in a resin with an optimum set of properties. Finally, a research work made by Mashouf and al[27] using DGEBA, EVO and sebacic acid as a curing agent was done to study only the curing kinetics of the reaction. To the best of our knowledge, no study described already the mechanical properties of blends of DGEBA and EVO cured with aliphatic dicarboxylic acid. Futhermore, our study enabled to compare DGEBA blends with other bi- and a tri- epoxydes. In addition to improve mechanical properties, an interesting aspect of these new epoxy-acid based networks is their shape memory behavior. Shape memory materials can "memorize" a permanent shape, be deformed to fix a temporary shape, and recover its permanent shape thank to a stimulus such as heat. They have been widely studied[28] and applications of such materials are found in health[29], electronic[30], space[31] and textile[32]. Among shape memory polymers, four classes are distinguished[33]: covalently crosslinked glassy thermoset networks (I), covalently cross-linked semicrystalline networks (II), physically

\section{ACCEPTED MANUSCRIPT}


cross-linked glassy copolymers (III) and physically cross-linked semi-crystalline block copolymers (IV). Epoxy-acid based networks described in this work belong to class (I), with a sharp $T_{\mathrm{g}}$ and rubbery elasticity above $T_{g}$. This class of materials is known for excellent shape recovery from temporary shape to permanent shape, thanks to rubbery elasticity and absence of molecular slippage between chains due to chemicals crosslinking. However, because of the covalent nature of the permanent shape, most of class I materials cannot be reshaped. Fortunately, our epoxy-acid based networks showed vitrimer behavior which enable them to be reshaped to several permanent shapes. Vitrimer based networks are able to change their topologies through bond exchange reactions[34-36]. Within epoxy-based materials, the chemical phenomenon behind covalent bond exchange is often based on transesterification reactions between hydroxyester linkages previously formed by the epoxycarboxylic acid reaction. Shape memory properties of our thermoset polyesters were quantified by cyclic thermo-mechanical tests[37] and stress relaxation tests were performed to assess vitrimer behavior with and without catalyst[38]. Although shape memory and vitrimer behavior of epoxy-acid based network have been studied, no work deals with blends of EVO with commercial epoxydes cured with a dicarboxylic acid.

\section{Materials}

In this paper, waste frying sunflower oil (WSO) was used instead of virgin sunflower oil (VSO). During frying, fat can be subjected to oxidation, hydrolysis, cyclization, isomerization and polymerization[39]. Therefore, the waste frying sunflower oil was analyzed to see if was not too decomposed by the frying process (industrial food use). Nuclear magnetic resonance spectroscopy $\left({ }^{1} \mathrm{H} N M R, \mathrm{CDCl}_{3}, 400 \mathrm{MHz}\right)$ confirmed that the number of unsaturations by triglyceride was not so different between the two oils. There were 4.1 unsaturations for the virgin sunflower oil and 3.8 unsaturations in average for the waste frying sunflower. It means that only few unsaturations were lost during long term heating [40]. Regarding the possible byproducts produced here, no signal was detected around $3 \mathrm{ppm}$, which means no epoxide was detected. Moreover, free fatty acids, which can appear as a result of hydrolysis, can further undergo oxidation reactions. Peroxide and hydroperoxides are formed. These primary products are rapidly decomposed in secondary products, such as ketones, alcohols, aldehydes or hydrocarbons [41]. No signs of such products were detected. Actually, ${ }^{1} \mathrm{H}$ NMR spectra of WSO and VSO are very similar (corresponding spectra with related proton integrations are displayed in SI). Epoxidized frying sunflower oil (ESO) was obtained following a procedure already described by our research group[22]. Waste frying sunflower oil $(300 \mathrm{~g}, 0.31 \mathrm{~mol}, 1$ equiv.), toluene $(1.4 \mathrm{~L})$, and formic acid $(29 \mathrm{~mL}$, $0.77 \mathrm{~mol}, 2.4$ equiv.) were mixed into a well stirred reactor. Hydrogen peroxide (35\%wt in water) $\left(201 \mathrm{~mL}, 2.68 \mathrm{~mol}, 8.4\right.$ equiv.) was added dropwise to the reaction mixture at $50^{\circ} \mathrm{C}$. After $26 \mathrm{~h}$ at this temperature, saturated sodium bicarbonate was added and the aqueous phase was extracted with ethyl acetate. The combined organic phases were dried with $\mathrm{MgSO}_{4}$ and then concentrated under reduced pressure. Nuclear magnetic resonance spectroscopy confirmed the epoxidation of all double bonds of the starting oil (Fig 1). ${ }^{1} \mathrm{H} \mathrm{NMR} \mathrm{CDCl}_{3}, 400 \mathrm{MHz} \delta$ (ppm) 0.79-0.98 (t, 9H, $\left.\mathrm{CH}_{3}\right), 1.17-1.90(\mathrm{~m}$, $84 \mathrm{H}, \mathrm{CH}_{2}$ ), 2.28-2.40 (t, $6 \mathrm{H}, \mathrm{CH}_{2}-\mathrm{C}=\mathrm{O}$ ), 2.87-3.24 ( $\mathrm{m}, 8.4 \mathrm{H}$, (3.8 epoxides per molecule), epoxides), 4.16 (dd, J = 4.4, $\left.11.9 \mathrm{~Hz}, 2 \mathrm{H}, \mathrm{CH}_{2}-\mathrm{O}\right), 4.31\left(\mathrm{dd}, \mathrm{J}=5.9,11.9 \mathrm{~Hz}, 2 \mathrm{H}, \mathrm{CH}_{2}-\mathrm{O}\right), 5.22-5.33(\mathrm{~m}, 1 \mathrm{H}, \mathrm{CH}-\mathrm{O})$. The 
average molecular weight was determined as $1000 \mathrm{~g} \cdot \mathrm{mol}^{-1}$ by MS-ESI (see SI). MS-ESI $\mathrm{m} / \mathrm{z}[\mathrm{M}+\mathrm{Na}]^{+}$: 956.15, 969.75, 983.85, 997.75, 1011.80, 1026.25, 1039.80, 1053.80, 1081.85, 1095.90.

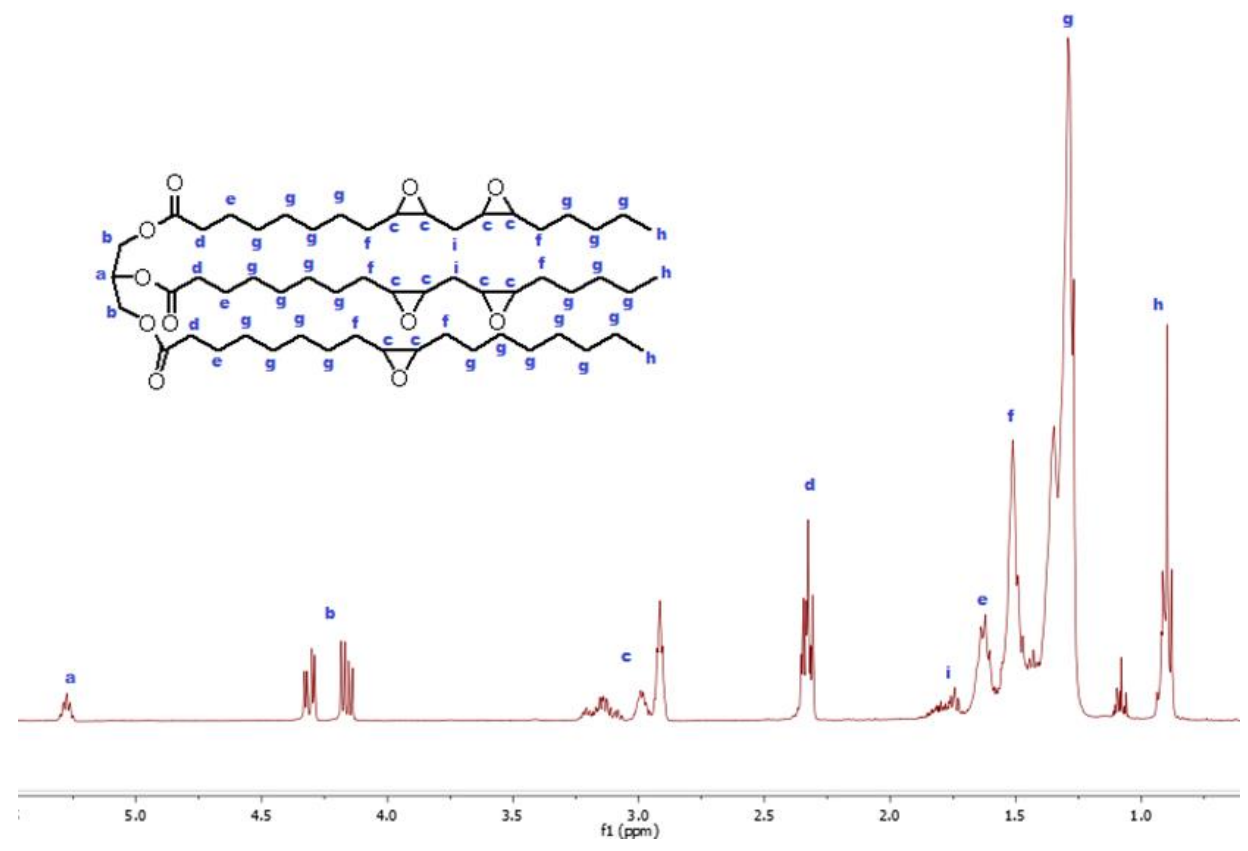

Fig 1: ${ }^{1} \mathrm{H}$ NMR of epoxidized frying sunflower oil (ESO)

(TRI) tris(4-hydroxyphenyl)methane triglycidyl ether; (EPO) 3,4-epoxycyclohexylmethyl-3',4'epoxycyclohexanecarboxylate; (DGEBA) bisphenol A diglycidyl ether were purchased from SigmaAldrich. (GA) Glutaric acid 99\% and 1-methylimidazole 99\% were purchased from Acros organics. All reagents were used as received without further purification; their chemical structures are shown in Fig 2.<smiles>CCOc1ccc(C(c2ccccc2)(c2ccc(OCC)cc2)c2ccc(OCC(C)C)cc2)cc1</smiles><smiles>O=C(OC1CCOC1)OC1CCOC1</smiles>
DGEBA GA

Fig 2: Chemical structure of the reagents : TRI : tris(4-hydroxyphenyl)methane triglycidyl ether; EPO: 3,4epoxycyclohexylmethyl-3',4'-epoxycyclohexanecarboxylate; DGEBA: ; bisphenol A diglycidyl ether; GA: Glutaric acid

\section{Synthesis of polyesters via epoxy ring opening reaction with glutaric acid}

Epoxidized waste frying sunflower oil (ESO), epoxy compounds (TRI, EPO, DGEBA) and glutaric acid (GA) were homogenized at $100^{\circ} \mathrm{C}$ and the reaction mixture was poured into rectangular silicon molds $(2.5 \mathrm{~mm} * 12.8 \mathrm{~mm} * 60 \mathrm{~mm})$. These molds were heated up into an oven at $180^{\circ} \mathrm{C}$ for $4 \mathrm{~h}$. No catalyst was used, except for samples used in the stress relaxation test. Those curing conditions were selected because they allowed the complete epoxy ring opening reaction of ESO with GA. Indeed, ATR-FTIR spectroscopy confirmed that the signals related to the ring vibration of cis epoxides around $815 \mathrm{~cm}^{-1}$ disappeared when ESO and GA were cured at $180^{\circ} \mathrm{C}$ for $4 \mathrm{~h}$. Conversely, a lower curing temperature $\left(150^{\circ} \mathrm{C}, 4 \mathrm{~h}\right)$ did not provide a full conversion of the epoxide functions (Fig 3). For samples containing DGEBA and TRI, the C-H out-of-plane bending of $p$-substituted benzenes at $830 \mathrm{~cm}^{-1}$ did not allow to verify the disappearance of the epoxide functions by ATR-FTIR spectroscopy. For convenience and comparability purposes, all samples were cured at $180^{\circ} \mathrm{C}$ for $4 \mathrm{~h}$. The disubstituted epoxides of ESO are

\section{ACCEPTED MANUSCRIPT}


less reactive than the monosubtituted epoxides of the additive compounds, it is therefore reasonable to assume that these conditions conduce to a full conversion of all epoxides present in the mixture.

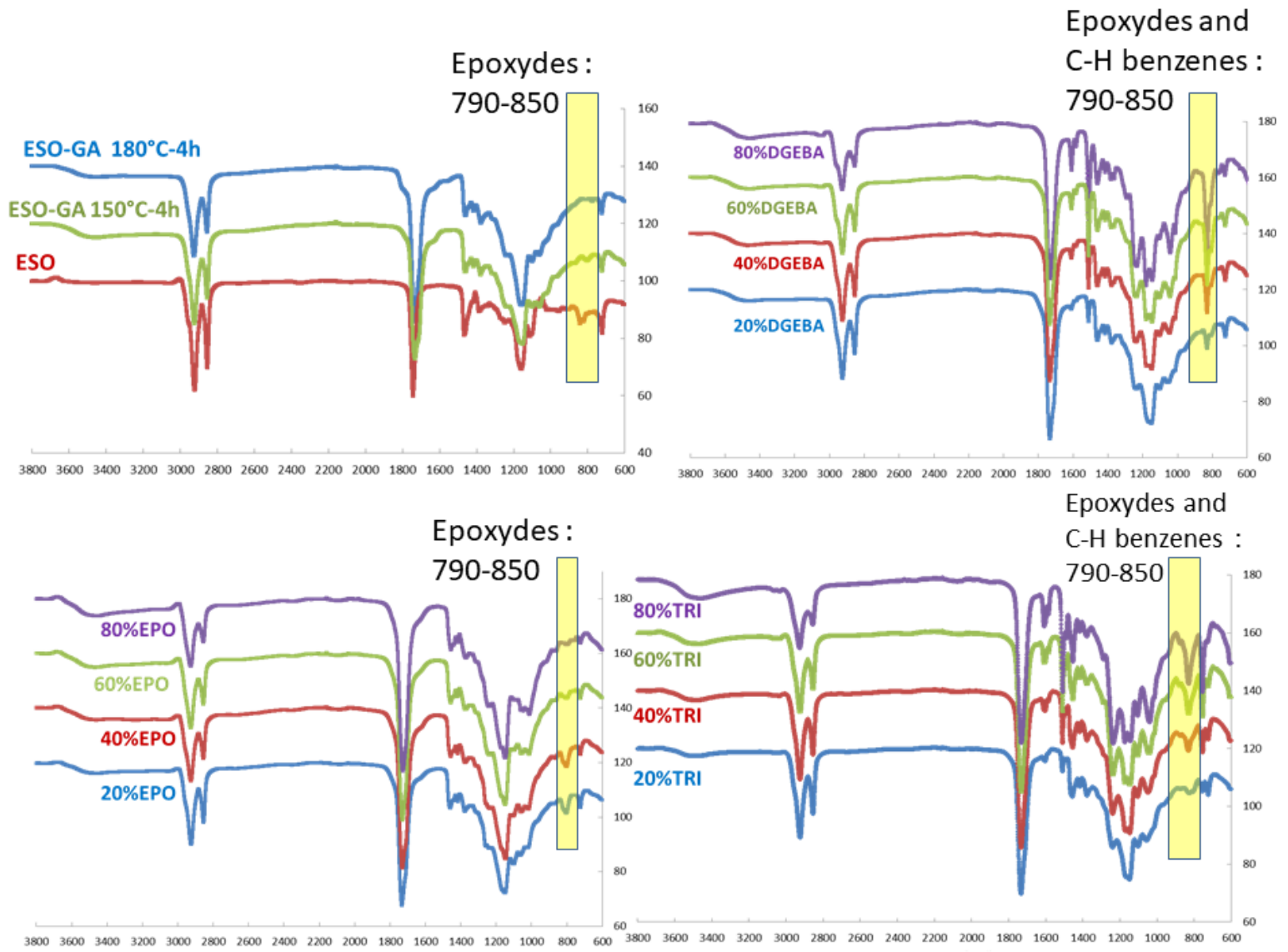

Fig 3: ATR-FTIR spectroscopy of ESO and cured samples

Three types of thermoset polyesters were made (Fig 4) with different amount of epoxy compounds, ranging from $0 \%$ to $80 \%$ molar equivalent in regards to ESO. Epoxide and carboxylic acid functions were always kept in stoichiometric proportions. Epoxy equivalent weight (EEW), which is the weight of an epoxy resin containing exactly one mole of epoxy group is given for each formulation in Table 1.

Table 1: Epoxy equivalent weight (EEW) for each resin formulation.

\begin{tabular}{|c|c|c|c|}
\cline { 2 - 4 } \multicolumn{1}{c|}{} & \multicolumn{3}{c|}{ Epoxy equivalent weight $\left(\mathbf{g} \cdot \mathbf{m o l}^{-1}\right.$ ) } \\
\hline $\begin{array}{c}\text { Molar equivalent } \\
\text { di/tri epoxy vs ESO }\end{array}$ & ESO-TRI & ESO-DGEBA & ESO-EPO \\
\hline $0 \%$ & 225.28 & 238.09 \\
$20 \%$ & 210.83 & 221.75 & 211.14 \\
$40 \%$ & 194.34 & 209.81 & 191.45 \\
$60 \%$ & 175.44 & 193.58 & 164.69 \\
$80 \%$ & & & \\
\cline { 2 - 4 }
\end{tabular}




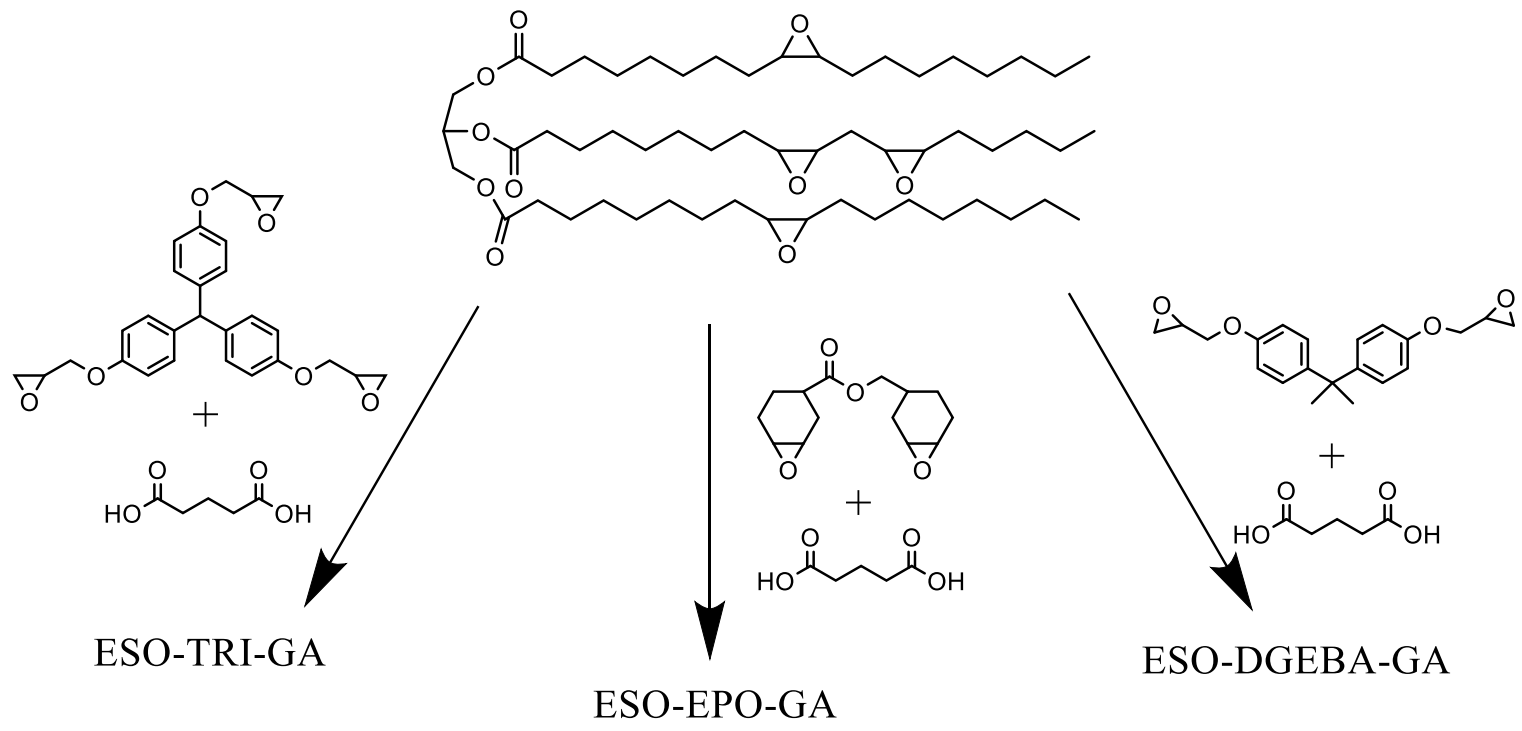

Fig 4: Three types of thermoset polyesters were made: "TRI-0\% to $80 \% "$;"EPO-0\% to $80 \% "$;"DGEBA-0\% to $80 \%$ " and cured at $180^{\circ} \mathrm{C}$ for $4 \mathrm{~h}$.

\section{Methods}

\section{Dynamic mechanical analysis (DMA)}

The dynamic mechanical properties of the cured samples were measured with a TA Instruments Q800 Dynamics Mechanical Analyzer with a dual cantilever clamp, at a frequency of $1 \mathrm{~Hz}$. Specimens of rectangular cross-sections $(2.5 \mathrm{~mm} \times 12.8 \mathrm{~mm})$ were tested, with a $37 \mathrm{~mm}$ span. The temperature ranged from -100 to $150^{\circ} \mathrm{C}$ with a scanning rate of $3^{\circ} \mathrm{C} \cdot \mathrm{min}^{-1}$. The storage modulus $\left(E_{f}^{\prime}\right)$, loss modulus $\left(E_{f}{ }^{\prime \prime}\right)$ and loss factor $(\tan \delta)$ of the cured samples were measured as a function of the temperature.

\section{Hardness}

Hardness was measured by a penetration test on a Shimadzu AGS-X fitted with cylinder probe $(3 \mathrm{~mm}$ diameter). The pre-test speed was $1 \mathrm{~mm} \cdot \mathrm{min}^{-1}$ until the probe touched the surface and reached a force of $0.2 \mathrm{~N}$. Then, penetration to a depth of $1 \mathrm{~mm}$ into the sample was done at a speed of $0.5 \mathrm{~mm} \cdot \mathrm{min}^{-1}$. Hardness was reported as the force required to penetrate $1 \mathrm{~mm}$ into the sample. All experiments were performed at $20^{\circ} \mathrm{C}$.

\section{Tensile testing}

Tensile strength analysis was carried out using a Shimadzu Autograph AGS- $X$ with $1 \mathrm{kN}$ load cell at an operation speed of $5 \mathrm{~mm} \cdot \mathrm{min}^{-1}$. Specimens of rectangular cross-sections $(2.5 \mathrm{~mm} \times 12.8 \mathrm{~mm})$ with a length of $40 \mathrm{~mm}$ were tested and the distance between clamps was $30 \mathrm{~mm}$. Young's modulus was calculated using TRAPEZIUM-X software. At a near zero stress, $1 \mathrm{~N}$ and $5 \mathrm{~N}$ in our case, the relation between stress and strain is linear. The slope of the line was taken as the Young's modulus. All experiments were performed at $20^{\circ} \mathrm{C}$. 


\section{Shape memory}

In order to quantify the shape memory performance of the sample, a control strain cyclic test was designed under DMA Q800 strain rate mode, using dual cantilever clamp. The samples were preheated at $\mathrm{T}_{\mathrm{g}}+40^{\circ} \mathrm{C}$ and then a strain deformation was applied. The strain was held constant while the sample was cooled down to $\mathrm{T}_{\mathrm{g}}-40^{\circ} \mathrm{C}$. The strain was then released and the sample was heated back up to $\mathrm{T}_{\mathrm{g}}+40^{\circ} \mathrm{C}$ while the length recovery was monitored. This heat-cool-heat procedure was cycled five times. The fixity ratio $\left(R_{f}\right)$ characterizes the ability of the sample to fix the strain imparted during the deformation step after cooling and unloading. The recovery ratio $\left(R_{r}\right)$ characterizes the ability of the sample to recover the permanent strain after reheating above $T_{g}$. $R_{f}$ and $R_{r}$ were calculated with the following equations[42]:

$$
\begin{gathered}
R_{f}(n)=\frac{\varepsilon_{u}(n)}{\varepsilon_{m}(n)} \times 100 \% \\
R_{r}(n)=\frac{\varepsilon_{u}(n)-\varepsilon_{p}(n)}{\varepsilon_{u}(n)-\varepsilon_{p}(n-1)} \times 100 \%
\end{gathered}
$$

Were $\varepsilon_{u}, \varepsilon_{m}, \varepsilon_{p}$ and $n$ respectively represent the strain after unloading, the strain before unloading, the residual strain after heat-induced recovery and the cycle number.

\section{Stress relaxation}

In order to quantify the transesterification rate occurring in epoxy vitrimers, stress relaxation was performed on a TA Instruments Q800 Dynamic Mechanical Analyzer with a dual cantilever clamp. Specimens of rectangular cross-sections $(2.5 \mathrm{~mm} \times 12.8 \mathrm{~mm})$ with a length of $40 \mathrm{~mm}$ were tested, with a $37 \mathrm{~mm}$ span. After equilibration at $180^{\circ} \mathrm{C}$, a deformation of $3 \%$ was applied and the relaxation modulus was recorded for $180 \mathrm{~min}$. A comparison of samples with and without transesterification catalyst was made. 1-methylimidazole (5.0 mol\%) was used as the transesterification catalyst[38].

\section{Results and discussion}

In total, thirteen different samples were prepared (Table 1). TRI, DGEBA and EPO compounds were selected considering their commercial availability, their low molecular weight that facilitates fast curing reaction and the presence of aliphatic or aromatic rings for mechanical property enhancement. The ring opening reaction occurred between epoxides coming from the ESO and from the epoxy compound, producing the cross-linked material through the formation of hydroxyester linkages. Our goal was to assess the minimum amount of TRI, DGEBA and EPO compounds to obtain materials with glass transition temperature above room temperature $\left(20^{\circ} \mathrm{C}\right)$. Consequently, it was possible to estimate the maximum of biobased epoxy content for each of three different materials (ESO-TRI-GA, ESO-DGEBA-GA, ESO-EPO-GA) that permits to have good mechanical properties at room temperature $\left(20^{\circ} \mathrm{C}\right)$ as well as the possibility to perform shape memory experiments at this temperature.

\section{ACCEPTED MANUSCRIPT}




\section{Dynamic mechanical analysis (DMA)}

After curing all the samples, visual control permitted to determine that ESO-TRI-GA samples should have respectively higher $\mathrm{T}_{\mathrm{g}}$ than ESO-DGEBA-GA and ESO-EPO-GA compounds. Therefore, all samples containing TRI and DGEBA-60\% and EPO-60\% were selected for a complete study by DMA. Influence of the concentration of TRI on modulus, $\mathrm{T}_{\mathrm{g}}$ and crosslinking density was studied in addition to the type of epoxy compound included into the material. Crosslinking densities $(\rho)$ for cured polyesters network were calculated from the storage modulus $\left(E^{\prime}\right)$ in the rubber region over the glass transition temperature according to the rubber elasticity theory[43,44]:

$$
\rho=\frac{E^{\prime}}{\varphi^{*} R^{*} T}
$$

$\mathrm{E}^{\prime}$ is the storage modulus at $\mathrm{T}=\mathrm{T}_{\mathrm{g}}+30^{\circ} \mathrm{C}$. $\mathrm{T}$ is often used as the $\mathrm{T}$ value in the equilibrium storage modulus $[45,46]$. $R$ and $T$ are the gas constant and absolute temperature at $T_{g}+30^{\circ} \mathrm{C}$, respectively. $\varphi$ is the front factor. This parameter depends on the functionality of the network junctions. For most networks it can be approximated to 1[47]. One must take into account that no differentiation is made between physical or chemical crosslinking within the $\rho$ value.

Crosslinking density increases with the amount of epoxyde content (Table 2). It varies from 2.3 mol..' ${ }^{1}$ with $0 \%$ of TRI to 36.5 mol.L ${ }^{-1}$ with $80 \%$ of TRI. In the literature, crosslinking density was calculated in the same way for similar thermoset polyesters. One was made of epoxidized perilla oil cured with a aromatic diacid[48], another one was epoxidized linseed oil cured with succinic acid[49] and a last one was epoxidized soybean oil cured with maleopimaric acid[50]. The resulting materials respectively had a $\rho$ of 3 mol.L-1, 7.2 mol. $\mathrm{L}^{-1}$ and between 0.37 and $6.58 \mathrm{~mol}^{-\mathrm{L}^{-1}}$ for the last ones. Therefore, a $\rho$ of 2.3 mol. $L^{-1}$ for ESO cured with GA is in the same order of magnitude. Every TRI molecule is potentially a chemical node of reticulation which explains why $\rho$ increases along with the percentage of TRI.

Table 2: Glass transition temperatures and crosslinking densities measured by DMA

\begin{tabular}{|cccc|}
\hline Samples & $\mathbf{T}_{\mathbf{g}}\left({ }^{\circ} \mathbf{C}\right)$ & $\begin{array}{c}\mathbf{E}^{\prime}(\mathbf{M P a}) \text { at } \\
\left(\mathbf{T}=\mathbf{T}_{\mathbf{g}}+\mathbf{3 0} \mathbf{}^{\circ} \mathbf{C}\right)\end{array}$ & $\boldsymbol{\rho}\left(\mathbf{m o l}^{\left.-\mathbf{L}^{-1}\right)}\right.$ \\
\hline TRI-0\% & 6 & 5.4 & 2.3 \\
TRI-20\% & 16 & 17.6 & 6.6 \\
TRI-40\% & 34 & 36.2 & 12.9 \\
TRI-60\% & 59 & 47.3 & 15.6 \\
TRI-80\% & 102 & 123.1 & 36.5 \\
\hline EPO-60\% & 27 & 16.4 & 5.8 \\
\hline DGEBA-60\% & 28 & 26.1 & 9.4 \\
\hline
\end{tabular}

The dynamic mechanical properties, storage modulus and damping factor (tan $\delta$ ), of the ESO-TRI-GA are shown in Fig 5. Storage modulus characterizes the ability of the material to restore mechanical energy whereas loss modulus characterizes the ability to dissipate mechanical energy into heat. The damping factor is the ratio of the loss modulus on the storage modulus. High moduli at low temperature correspond to the glassy state which is followed by an $\alpha$ relaxation and a rubber region. The storage modulus ( $\left.E^{\prime}\right)$ increases with the concentration of TRI. At $-25^{\circ} \mathrm{C}$, it varies from $0.5 \mathrm{GPa}$ for $0 \%$ of TRI to $1 \mathrm{GPa}$ for $80 \%$ of TRI. Those values of $\mathrm{E}^{\prime}$ are typical for epoxidized vegetable oil cured with

\section{ACCEPTED MANUSCRIPT}


dicarboxylic acid. Indeed, at $-25^{\circ} \mathrm{C}$, the storage modulus of epoxidized linseed oil cured with sebacid acid[49] is aroung $1 \mathrm{GPa}$ and $\mathrm{E}^{\prime}$ value for epoxidized broccoli seed oil cured with glutaric acid[22] is 0.8 GPa. The increase of $E^{\prime}$ along with the percentage of TRI is related to a higher crosslinking density, a higher number of aromatic rings and a diminution of aliphatic chains when the concentration of TRI increases. TRI is a tri-functional compounds whereas EPO and DGEBA are bi-functional compounds. Thus every TRI molecule is potentially a node of crosslinking. It explains why the calculated crosslinking density is higher for TRI-60\% than for EPO-60\% and DGEBA-60\%. The same explanation[51] can be made for the glass transition temperature $\left(\mathrm{T}_{\mathrm{g}}\right)$ associated with the tan $\delta$ peak: a higher crosslinking density leads to higher density which is less free volume. As molecular motion is restricted, more energy is necessary to activate the motion of molecular segment. It explains why glass transition temperature increases along with the crosslinking density. $T_{\mathrm{g}}$ increases from $6^{\circ} \mathrm{C}$ for TRI- $0 \%$ to $102^{\circ} \mathrm{C}$ for TRI-80\%. This large range of glass transition temperature can be interesting for potential applications[52]. By increasing the percentage of TRI, the width of $\alpha$ transition also increases. This phenomenon can be explain by the increase of the crosslinking density and/or by the increase modification of the polyesters backbone structure. When the molar percentage of TRI exceeds $40 \%$, $\mathrm{T}_{\mathrm{g}}$ of the material is above room temperature $\left(20^{\circ} \mathrm{C}\right)$, making possible shape memory experiences with temporary shapes fixed at room temperature. Regarding DGEBA and EPO compounds, it required molar percentage above $60 \%$ to obtain $\mathrm{T}_{\mathrm{g}}$ above $20^{\circ} \mathrm{C}$ (Table 3 ).

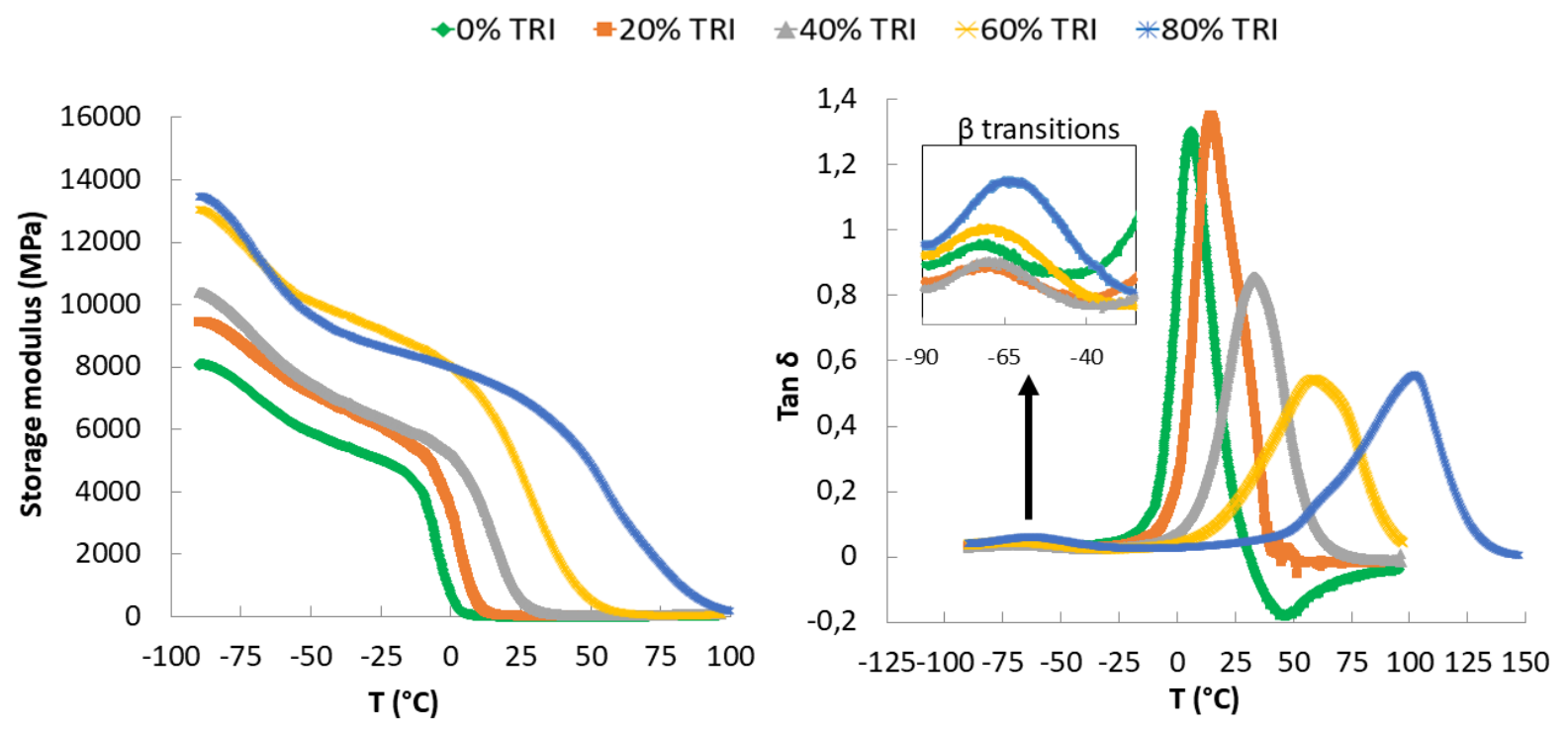

Fig 5: Storage modulus and damping factor of the "TRI" thermoset polyesters as a function of temperature

Regarding biobased epoxy content, ESO-TRI-GA is more interesting than ESO-DGEBA-GA and ESO-EPOGA. Indeed, sample TRI- $40 \%$ has a $\mathrm{T}_{\mathrm{g}}$ of $34^{\circ} \mathrm{C}$ which is slightly above those of DGEBA-60\% and EPO-60\%. $\mathrm{T}_{\mathrm{g}}$ value for ESO cured with glutaric acid is $6^{\circ} \mathrm{C}$. This value is similar to the one of an epoxidized linseed oil cured with another aliphatic dicarboxylic acid : sebacic acid. In that case, $T_{g}$ is $5.8^{\circ} \mathrm{C}$. In order to increase glass transition temperature of ESO blends, it is not only possible to use an aromatics trifunctional epoxyde compound or an aromatic diacid[22], but it is also possible to use an anhydride as curing agent instead of aliphatic dicarboxylic acid. Indeed, Altuna and al[26] used methyltetrahydrophthalic anhydride as a crosslinking agent to cure a blend of epoxidized soybean oil and DGEBA and they obtained $\mathrm{T}_{\mathrm{g}}$ from $57^{\circ} \mathrm{C}$ to $108^{\circ} \mathrm{C}$ by varying the percentage of DGEBA from $0 \%$ to $100 \%$. By curing epoxidized soybean oil a cycloaliphatic anhydride, Pan and al[53] obtained a

\section{ACCEPTED MANUSCRIPT}


thermoset polyester with a $\mathrm{T}_{\mathrm{g}}$ of $24.8^{\circ} \mathrm{C}$. High $\mathrm{T}_{\mathrm{g}}$ for epoxy based materials can be required for composite materials or electrical insulators[54].

The $\beta$ transition is a low-temperature relaxation process associated with polymer backbone motion usually referred to as the $\beta$-relaxation process. The main chain $\beta$-relaxation process involves local motions of the polymer chain backbones that do not require cooperative motion of surrounding chains[55]. On Fig 5, $\beta$ transitions of the cured thermoset polyesters occur around $-65^{\circ} \mathrm{C}$ and slightly increases with the percentage of TRI. It might be associated with the motions of small segments between nodes of reticulation, which become stiffer by increasing the amount of TRI.

\section{Static mechanical properties: Tensile testing and hardness}

Young's modulus $(E)$, stress $\left(\sigma_{b}\right)$ and strain at break of the thermoset polyesters are displayed in Fig 6, 7, 8. Influence of the nature and concentration of epoxy compounds are studied. Sample with $80 \%$ of TRI did not break. $E$ and $\sigma_{\mathrm{b}}$ increase along with the crosslinking density, which is related with the decrease of epoxy equivalent weight. The three epoxy compounds do not have the same impact on mechanical properties. Young's modulus for ESO-EPO-GA and ESO-DGEBA-GA polyesters with 20\%, $40 \%$ and $60 \%$ of bifunctional epoxy compounds, is between 1 and $3 \mathrm{MPa}$ and it drastically increases for $80 \%$ of EPO and DGEBA. Those values correspond with values of similar epoxy thermosets. For example, epoxidized linseed oil cured with aliphatic dicarboxylic acids[49] displays a $E$ of 3.9 MPa with suberic acid and 4.0 MPa with sebacic acid. $E$ above $200 \mathrm{MPa}$ are obtained for epoxidized soybean cured with an anhydride[50]. 80\% of DGEBA or EPO are needed to reach those values of $E$ with ESO and GA. ESO-TRI-GA polyesters shows a significant increase of both $E$ and $\sigma_{b}$ for percentage above $60 \%$. ESO-TRI-GA with $60 \%$ of TRI has a $E$ of $320 \mathrm{MPa}$ and it reaches $650 \mathrm{MPa}$ with $80 \%$ of TRI. This last value of $E$ is interesting for applications where high mechanical properties are needed. For example a commercial epoxy resin made of DGEBA and cured with an aromatic diamine has a $E$ of $2.71 \mathrm{GPa}[56]$. Mechanical properties of ESO-TRI-GA polyesters increases sharply for TRI percentages above $40 \%$ and for ESO-EPO-GA and ESO-DGEBA-GA polyesters it is for percentage above $60 \%$. Non-linear increase of $E$ and $\sigma_{b}$ with epoxy compounds percentage is observed. Explanation behind this non-linear behavior is related with the glass transition temperature. Indeed, as mentioned before, $\mathrm{T}_{\mathrm{g}}$ values for EPO-60\% and DGEBA- $60 \%$, are respectively $28^{\circ} \mathrm{C}$ and $27^{\circ} \mathrm{C}$. These values are close to ambient temperature, thus the network conformation is between rubbery and glassy state. $\mathrm{T}_{\mathrm{g}}$ value for TRI- $60 \%$ cured at $180^{\circ} \mathrm{C}$ is $59^{\circ} \mathrm{C}$, thus the network conformation is in a glassy state. It is well-known that above $\mathrm{T}_{\mathrm{g}}$, mechanical properties change drastically[57]. In the glassy state, influence of intermolecular packing, arising from the intermolecular forces, is considered to be predominant factor which determines the Young's modulus value for epoxy resins[58]. Among the epoxy compounds, TRI provides the highest glass transition temperatures because of an important number of aromatic rings in ESO-TRI-GA polyesters which give high rigidity to the backbone structure, and a higher crosslinking density. Unlike EPO, DGEBA also possesses aromatic rings. If we follow the previous explanation, DGEBA-60\% should have higher $\mathrm{T}_{\mathrm{g}}$ than $\mathrm{EPO}-60 \%$, but it is not the case. Explanation for this observation can originate from the structure of the EPO which is a smaller molecule than DGEBA, therefore the number of rings per polymer segments is higher than with DGEBA, which induces an increased rigidity even without aromatic rings. Stress at break value for ESO-GA is $0.4 \mathrm{MPa}$. Similar values are found in a previous study for epoxidized linseed oil cured with aliphatic dicarboxylic acids. When the curing agent is sebacic acid, $\sigma_{b}$ is $0.7 \mathrm{MPa}$ and with suberic acid $\sigma_{\mathrm{b}}$ is $0.6 \mathrm{MPa}$ [49]. With $80 \%$ of EPO and DGEBA, $\sigma_{\mathrm{b}}$ reaches 13 and $15 \mathrm{MPa}$ and it is above $18 \mathrm{MPa}$ for $80 \%$ of TRI. Those values are interesting where mechanical strength are needed. Those values are in the same order of magnitude of epoxidized soybean oil cured with an

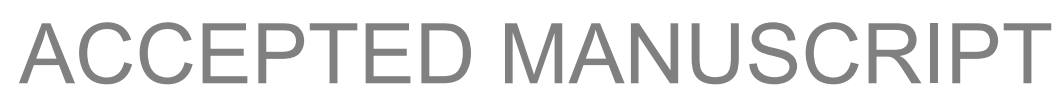


anhydride containing an aromatic ring in presence of a catalyst[50]. Reported values of tensile strength, which the same as stress at break for glassy thermoset, are ranged between 9 and $30 \mathrm{MPa}$ in this quoted study.

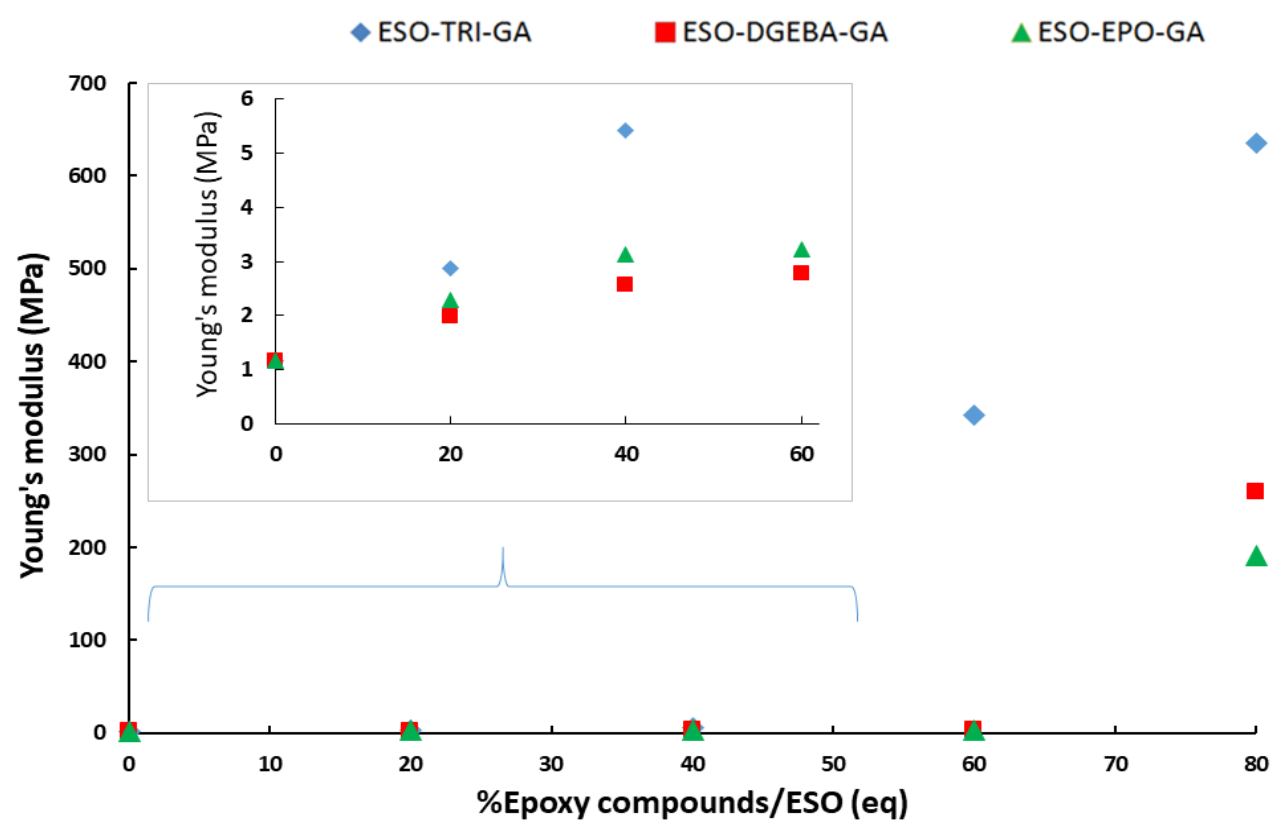

Fig 6: Young's modulus of thermoset polyesters with different natures and concentrations of epoxy compounds

In their rubbery state, samples ESO-DGEBA-GA and ESO-EPO-GA display very low Young's modulus, between 1 and $3 \mathrm{MPa}$ and low tensile strength. This indicates low crosslinking density. Indeed, in the rubbery state, only crosslinking nodes have an impact on mechanical properties. Besides, for samples ESO-DGEBA-GA and ESO-EPO-GA, chemical crosslinking should theoretically decrease because the amount of ESO decreases, and it is replaced by bi-functional compounds. However, $E$ or $\sigma_{b}$ stays almost constant between $0 \%$ and $60 \%$ for samples ESO-DGEBA-GA and ESO-EPO-GA. This indicates that there is an increase of the physical crosslinking density as the content of bi-functional epoxy increases, which compensates the decrease of the chemical crosslinking density. For samples ESO-TRI-GA, ESO molecules are replaced by tri-functional epoxy compounds, which are also potentially node of chemical crosslinking. In the rubbery state of ESO-TRI-GA, between 0 and $20 \%, E$ and $\sigma_{b}$ slightly increases which might be explained by either an increase of the chemical or the physical crosslinking. 


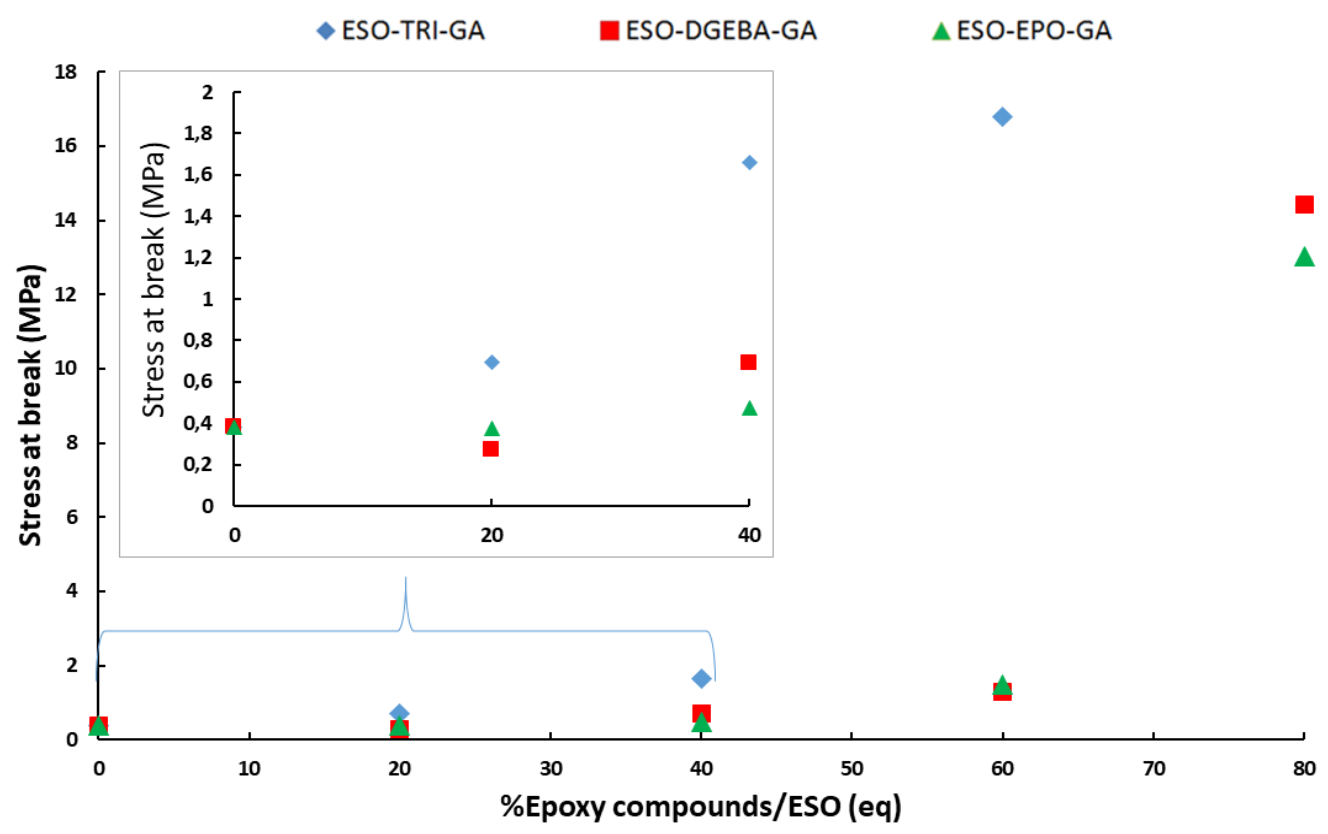

Fig 7: Stress at break of thermoset polyesters with different natures and concentrations of epoxy compounds

In Fig 8, strain at break values for each sample except TRI-80\% are displayed. For all samples, and particularly for ESO-DGEBA-GA, strain at break is lower at $20 \%$ than at $0 \%$ of epoxy compounds. At $20^{\circ} \mathrm{C}$, samples with $20 \%$ of commercial epoxyde compounds are in there rubbery state. Intermolecular forces are absent and the samples behave as fluids with the crosslinking nodes acting as pinning points. Consequently, they are not able to support high loads and breaks down at low stresses, which happen at low extensions. From $0 \%$ to $20 \%$ crosslinking density increases (Table 3 ), which means more pinning points. Therefore, it is not surprinsing to see strain at break slightly diminishes from $0 \%$ to $20 \%$. The decrease is less obvious for TRI- $20 \%$. $\mathrm{T}_{\mathrm{g}}$ of TRI- $20 \%$ is $16^{\circ} \mathrm{C}$. At $20^{\circ} \mathrm{C}$ which is the temperature of the test, the sample is no longer in the rubbery state but between rubbery and glassy state, also called viscoelastic state. In this state, thermosets epoxy materials have higher ductility [58]. It is why strain at break for TRI-20\% is not lower than TRI-0\% even if it has a higher crosslinking density. It also explains why strain at break increases for almost all samples after $40 \%$ of epoxy compounds: samples are in their viscoelastic state. An exception is TRI-60\%. $\mathrm{T}_{\mathrm{g}}$ of TRI- $60 \%$ is $59^{\circ} \mathrm{C}$. It means that ESO-TRI-GA is no longer in his viscoelastic state but in his glassy state. In the glassy state, the network has low extensibility. Therefore, the sample breaks with lower extension than in his viscoelastic state. It seems that the highest strain at break are observed for samples which are in their viscoelastic state but the closest to their glassy state. With DGEBA-80\% and EPO-80\%, strain above $80 \%$ are reached. In the literature, epoxidized linseed oil cured succinic acid have a strain at break of $98 \%$ and a $\mathrm{T}_{\mathrm{g}}$ of $20^{\circ} \mathrm{C}$. This high strain is due to the fact that the sample is in his viscoelastic state. If it is cured with suberic acid or sebacic acid, strain at break is respectively $22 \%$ and $21 \%$ with $\mathrm{T}_{\mathrm{g}}$ of $4.1^{\circ} \mathrm{C}$ and $5.8^{\circ} \mathrm{C}$. At $20^{\circ} \mathrm{C}$ those samples are in their rubbery state. As previously explained, it is why strain at break at $20^{\circ} \mathrm{C}$ is much lower with suberic and sebacic acid than with succinic acid. This value of $21 \%$ is close to the $30 \%$ obtain with ESO cured with GA. 


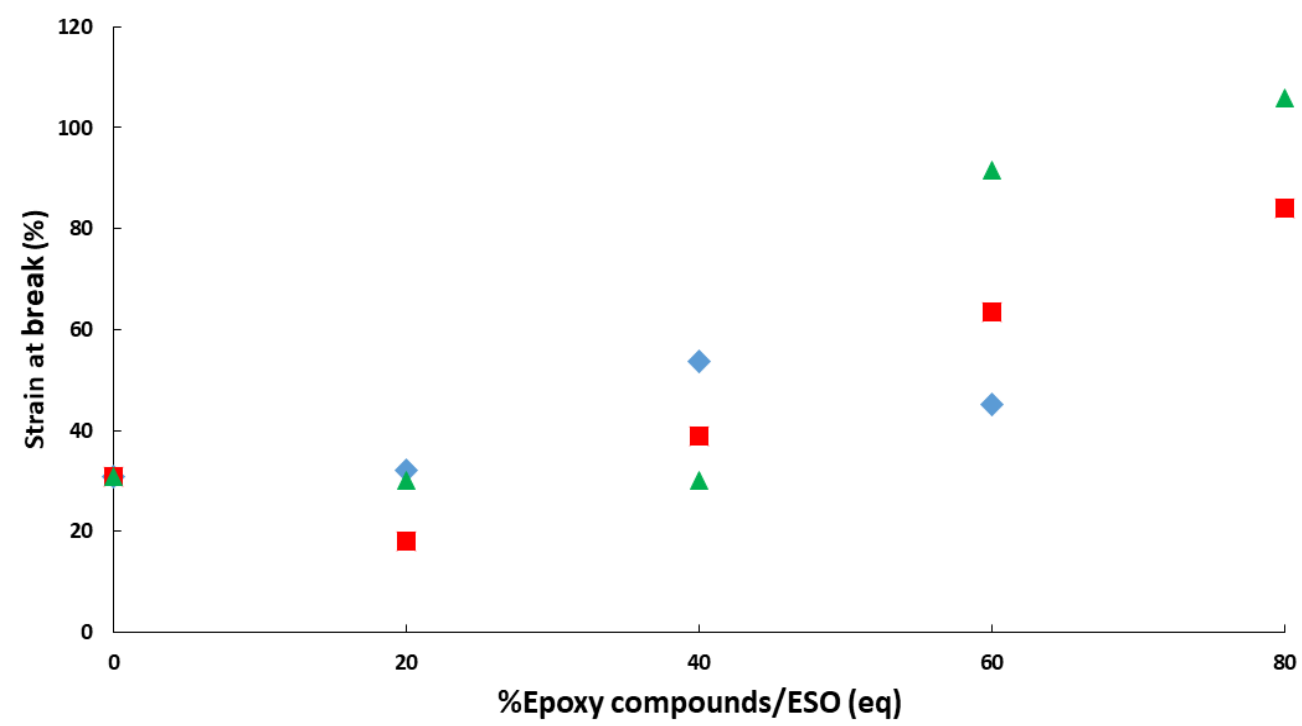

Fig 8: Strain at break of thermoset polyesters with different natures and concentrations of epoxy compounds

Evolution of hardness (Fig 9) values is similar to the evolution of $E$ or $\sigma_{b}$. In the rubbery state, samples are soft and increasing the percentage of epoxy compounds has very small impact on hardness. However, in the glassy state, i.e after $40 \%$ for TRI and after $60 \%$ for DGEBA and EPO, hardness values sharply increase. Once again, it confirmed that TRI permits to obtain polyesters with higher stiffness. Hardness is a needed property for protective coatings application, which means high $\mathrm{T}_{\mathrm{g}}$ are needed.

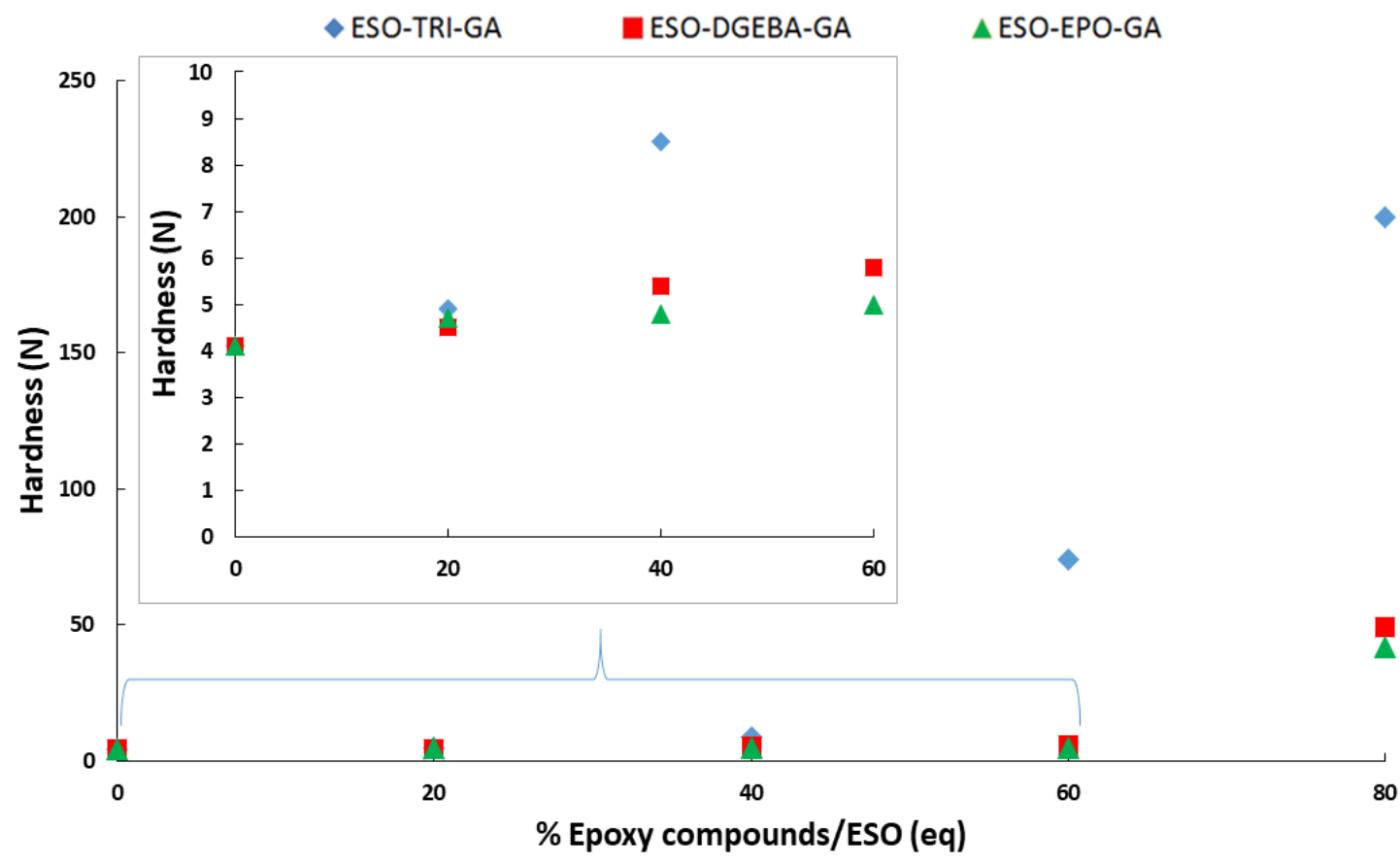

Fig 9: Hardness of thermoset polyesters with different natures and concentrations of epoxy compounds 


\section{Shape memory}

Investigation of the shape memory properties of these three materials was carried out, but only for materials including $60 \%$ of epoxy (TRI, DGEBA, EPO) compounds. As previously mentionned, we were interested by materials with a $T_{g}$ above room temperature and with the highest possible content of biobased epoxy. Fig $\mathbf{1 0}$ shows the result of a six-cycle deformation-recovery test under control strain analysis mode for EPO-60\%. Same analysis was performed for TRI-60\% and DGEBA-60\% samples (see $\mathrm{SI}$ for graphics). Samples were pre-heated at $\mathrm{T}_{\mathrm{g}}+40^{\circ} \mathrm{C}$, a deformation of $3.5 \%$ using a dual cantilever clamp was applied and temperature was set to $\mathrm{T}_{\mathrm{g}}-40^{\circ} \mathrm{C}$. The deformation was then released, and resulting fixity ratio calculated. Fixity ratios of EPO-60\% and DGEBA-60\% are above $99 \%$ (Table 3) which demonstrate remarkable temporary shape fixity. Fixity ratios of TRI- $60 \%$ are lower but above $94 \%$, which is still a good fixity ratio. These values are similar with studies on shape memory behavior of epoxy resins $[38,59]$ where fixity ratios above $97 \%$ were obtained.

After releasing the strain, temperature was set to $\mathrm{T}_{\mathrm{g}}+40^{\circ} \mathrm{C}$ in order to quantify recovery ratio of the permanent shape. For all samples and every cycle, recovery ratios were above $99 \%$, which demonstrate the ability of these thermoset polyesters to fully recover their permanent shape. These results show excellent shape memory behavior of those thermoset polyesters. For comparison, recovery ratios ranging from $96.6 \%$ to $99.8 \%$ were obtained in studies of shape memory behavior of epoxy resins[59,60].

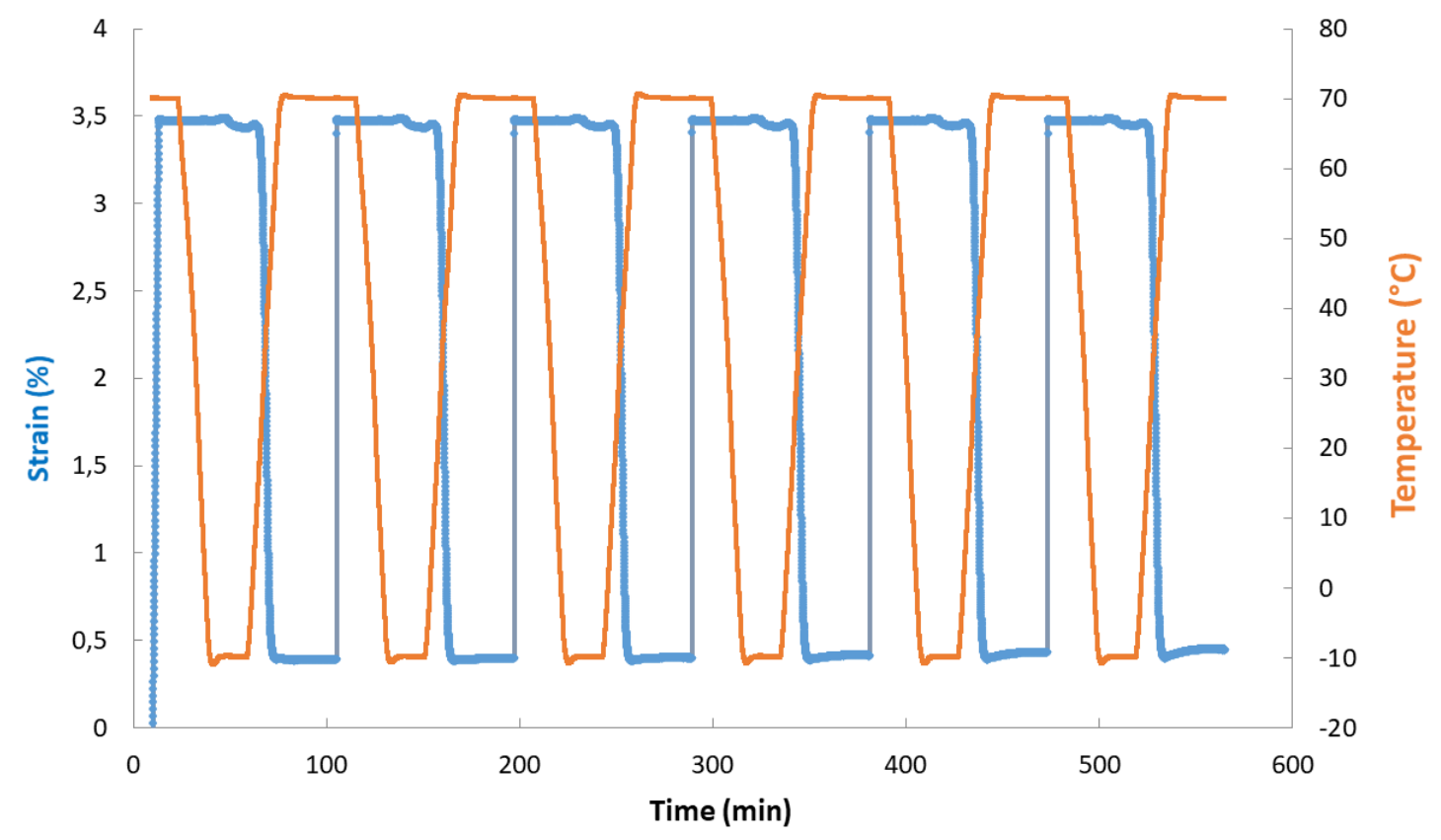

Fig 10: Deformation-recovery cyclic test for shape memory quantitative analysis of EPO-60\%

The driving force for shape recovery is entropic by nature[28]. It is energetically favorable for the 3D network to return to its most disordered conformation. Entropic stress generated in the rubbery state above $T_{\mathrm{g}}$ is stored below $T_{\mathrm{g}}$ because of a decreased mobility of polymer chain due to free volume diminution. By heating above $\mathrm{T}_{\mathrm{g}}$, entropic stress is removed allowing maximum disordered conformation of the 3D polymer network to be achieved, which corresponds to the permanent shape of the sample. Fixity ratios are lower for TRI-60\% potentially because this sample has a higher crosslinking density than DGEBA-60\% and EPO-60\%, which gives more strength to resist to the entropic stress generated in the rubbery state.

\section{ACCEPTED MANUSCRIPT}


Table 3: Shape memory parameters for samples EPO/DGEBA/TRi-60\%

\begin{tabular}{|c|c|c|}
\cline { 2 - 3 } \multicolumn{1}{c|}{} & Fixity ratios (\%) & Recovery ratio (\%) \\
\hline EPO-60\% & $>99$ & $99-100$ \\
DGEBA-60\% & $>99$ & $98-99$ \\
TRI-60\% & $>94$ & 100 \\
\hline
\end{tabular}

To better visualize the shape memory properties, qualitative shape memory performance with TRI$60 \%$ sample was carried out(Fig 11). A deformation at $95^{\circ} \mathrm{C}$ was applied manually and held as the sample TRI- $60 \%$ was cooled down in water at $10^{\circ} \mathrm{C}$. This temporary shape was then removed by immersion in water at $95^{\circ} \mathrm{C}$ and permanent shape 1 was recovered. Then by heating $1 \mathrm{~h}$ at $180^{\circ} \mathrm{C}$ a new permanent shape was given. The chemical phenomena enabling this permanent re-shaping are transesterification reactions between hydroxyester linkages[38] previously formed by the epoxycarboxylic acid ring opening. These covalent bond interchanges were first described by Leibler and coworkers[34], and materials having this specificity are called vitrimers. Some catalysts such as 1methylimidazole, zinc acetylacetonate or tributylamine[61] are known to enhance transesterification reactions but even without any catalyst, vitrimer-like behavior can be observed here. A temporary shape 2 was given to the sample with previously described protocol and the permanent shape 2 was recovered by immersion in hot water. It can be seen on Fig 11, that permanent shape 2 is not fully recovered, certainly because of the absence of a transesterification catalyst.

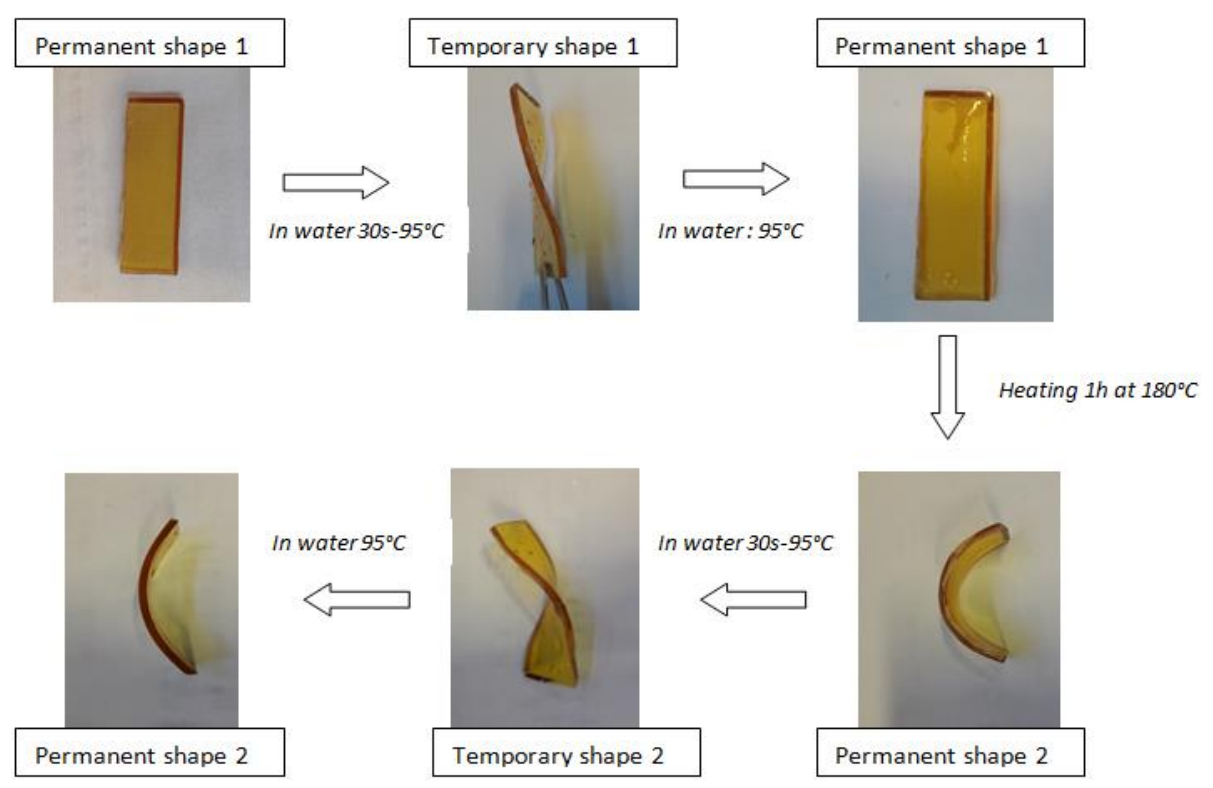

Fig 11: Qualitative demonstration of temporary and permanent shape modifications of sample TRI-60\%

In order to evaluate the influence of a catalyst on the transesterification reaction rate, stress relaxation experiments were performed in the presence or in the absence of catalyst. Indeed, transesterification reaction rate can be assessed by stress relaxation[62]. The relaxation modulus $E_{c}(t)$ of three samples: EPO-60\%, DGEBA-60\% and TRI-60\%, was studied as a deformation of 3\% in a dual cantilever clamp was held constant for $180 \mathrm{~min}$. The transesterification catalyst used was the 1-methylimidazole (5.0 mol\%). Samples containing the catalyst were : EPO-60\%-cat, DGEBA-60\%-cat and TRI-60\%-cat. Stress relaxation curves are displayed on Fig $\mathbf{1 2}$. Samples without catalyst have similar transesterification

\section{ACCEPTED MANUSCRIPT}


rate. After $3 \mathrm{~h}$ the $\mathrm{E}_{\mathrm{c}}(\mathrm{t})$ decreased by around $20 \%$ of its original value. This value is in the same order of magnitude than other vitrimers made out of vegetable oil[63] which do not contain transesterification catalyst. Samples containing catalyst have much faster transesterification reactions. Indeed, after $3 \mathrm{~h}$, the $E_{c}(t)$ of EPO-60\%-cat and DGEBA-60\%-cat decreased by around $60 \%$ of the original value. For sample TRI-60\%-cat the reaction is even faster. After $3 \mathrm{~h}$, the $E_{c}(t)$ value decreased by nearly $100 \%$. Two explanations can be given to understand why transesterification reactions are faster for TRI-60\%-cat. Theoretically, if it is assumed that the reaction is completed, the concentration of hydroxyester groups is higher for TRI-60\%-cat than for DGEBA-60\%-cat given their epoxy equivalent weight: 194.3 versus $209.8 \mathrm{~g} . \mathrm{mol}^{-1}$ respectively. Consequently, because the rate of a chemical reaction depends on the concentration of the reagents, transesterification rate is faster for TRI-60\%-cat than for DGEBA-60\%cat. The same explanation cannot be given to compare TRI-60\%-cat and EPO-60\%-cat because their EEW are very similar 194.3 and 191.5 g.mol ${ }^{-1}$, respectively. Transesterification rate should be slightly faster for EPO-60\%-cat than for TRI-60\%-cat. However, another parameter is known to influence the transesterification rate : the distance between hydroxyester groups[64]. As previously said, every molecule of TRI is potentially a crosslinking node which give a more compact network structure than polyester made with bifunctional compounds such as EPO and DGEBA. Therefore, hydroxyester groups are closer in TRI-60\%-cat than in EPO-60\%-cat, which could explain why the transesterification rate is faster with TRI-60\%-cat. Overall, no significant difference of transesterification rate was observed without catalyst but its presence exacerbated these differences, a clear impact on the reaction rate was observed. As expected, the use of 1-methylimidazole as a transesterification catalyst turned out to be a good choice to enhance the vitrimer behavior of these polyesters. A study of epoxy vitrimers based on DGEBA crosslinked with citric acid in presence of 1-methylimidazole indicates that the relaxation modulus lowest value was reached after about $5000 \mathrm{~s}$ at $160^{\circ} \mathrm{C}[64]$. This result indicates that to increase even more the vitrimer behavior of epoxy-acid based network, it requires not only a catalyst and a tri-functional epoxy compounds, but also to use a tri-functional curing agent.

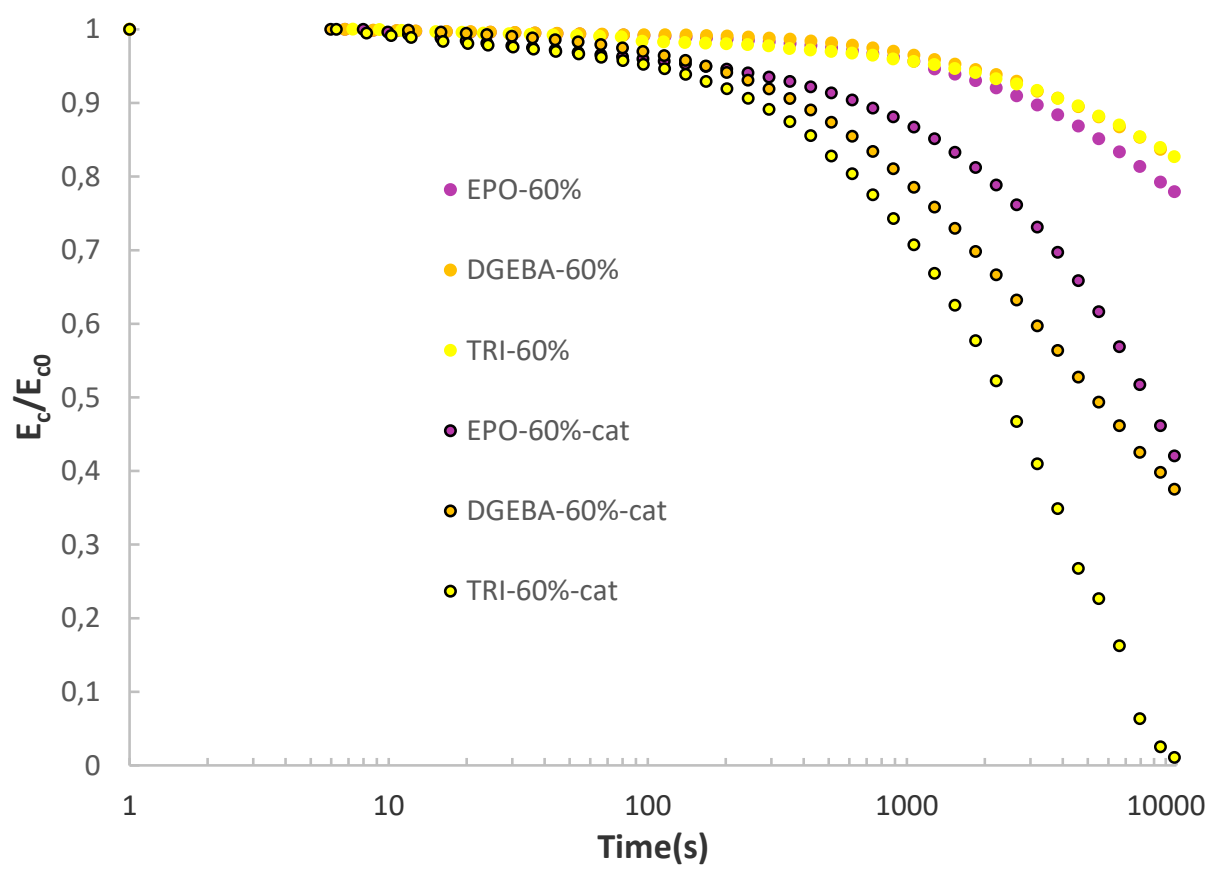

Fig 12: Stress relaxation of epoxy-acid vitrimers at $180^{\circ} \mathrm{C}$ 


\section{Conclusion}

The research work presented herein illustrates the possibility of enhancing mechanical properties of thermoset polyesters made out of epoxidized waste frying sunflower oil and glutaric acid by adding commercially available epoxy compounds. Tensile and hardness properties increase along with the amount of epoxy compound within the material. Polyesters made with tris(4-hydroxyphenyl)methane triglycidyl ether have the highest modulus, tensile strengths and hardness. At $20^{\circ} \mathrm{C}$, Young's modulus increases from $1 \mathrm{MPa}$ for TRI-0\% to $320 \mathrm{MPa}$ for TRI-60\% and stress at break from $0.4 \mathrm{MPa}$ to $17 \mathrm{MPa}$. Glass transition temperatures of the resulting polymers were ranged between $6^{\circ} \mathrm{C}$ and $102^{\circ} \mathrm{C}$, which gives a large choice for potential end-use applications. Among those applications, protective coatings can be consider, especially for TRI-80\% which has a hardness value of $200 \mathrm{MPa}$. Furthermore, excellent shape memory properties of formulations including $60 \%$ of epoxy additives were demonstrated by cyclic thermo-mechanical tests. Fixity ratios were above $94 \%$ and recovery ratios above $98 \%$ for all the tested materials. Those thermoset polyesters with epoxy-acid based network showed also vitrimer behavior thanks to transesterification reactions between hydroxyester groups. The use of a transesterification catalyst is nevertheless recommended to obtain good reaction rate. In a context of circular economy promotion, it is noticeable that waste frying oil can be advantageously used to make new materials with large range of mechanical properties and singular performances such as shape memory and vitrimer behavior. The mentioned application as protective coating is enhanced by the shape memory and vitrimer behavior of those materials, which are properties increasingly seek to make self-healing materials.

\section{Acknowledgements}

This work was supported by the "Association Nationale de la Recherche et de la Technologie ", Paris, France; and Tifany emballages, Saint-Malo, France.

\section{References}

[1] S.G. Tan, W.S. Chow, Biobased Epoxidized Vegetable Oils and Its Greener Epoxy Blends: A Review, Polym.-Plast. Technol. Eng. 49 (2010) 1581-1590. https://doi.org/10.1080/03602559.2010.512338.

[2] A.Z.M. Rus, Polymers from Renewable Materials, Sci. Prog. 93 (2010) 285-300. https://doi.org/10.3184/003685010X12797251639519.

[3] G. Lligadas, J.C. Ronda, M. Galià, V. Cádiz, Renewable polymeric materials from vegetable oils: a perspective, Mater. Today. 16 (2013) 337-343. https://doi.org/10.1016/j.mattod.2013.08.016.

[4] M.A.R. Meier, J.O. Metzger, U.S. Schubert, Plant oil renewable resources as green alternatives in polymer science, Chem. Soc. Rev. 36 (2007) 1788-1802. https://doi.org/10.1039/B703294C.

[5] M.D. Soucek, T. Khattab, J. Wu, Review of autoxidation and driers, Prog. Org. Coat. 73 (2012) 435-454. https://doi.org/10.1016/j.porgcoat.2011.08.021.

[6] P. Loulergue, M. Amela-Cortes, S. Cordier, Y. Molard, L. Lemiègre, J.-L. Audic, Polyurethanes prepared from cyclocarbonated broccoli seed oil (PUcc): New biobased organic matrices for incorporation of phosphorescent metal nanocluster, J. Appl. Polym. Sci. 134 (2017) 45339. https://doi.org/10.1002/app.45339.

\section{ACCEPTED MANUSCRIPT}


[7] M. Winnacker, B. Rieger, Biobased Polyamides: Recent Advances in Basic and Applied Research, Macromol. Rapid Commun. 37 (2016) 1391-1413. https://doi.org/10.1002/marc.201600181.

[8] D.D. Andjelkovic, B. Min, D. Ahn, R.C. Larock, Elucidation of Structural Isomers from the Homogeneous Rhodium-Catalyzed Isomerization of Vegetable Oils, J. Agric. Food Chem. 54 (2006) 9535-9543. https://doi.org/10.1021/jf0612124.

[9] C. Bueno-Ferrer, M.C. Garrigós, A. Jiménez, Characterization and thermal stability of poly(vinyl chloride) plasticized with epoxidized soybean oil for food packaging, Polym. Degrad. Stab. 95 (2010) 2207-2212. https://doi.org/10.1016/j.polymdegradstab.2010.01.027.

[10] M. Bocqué, C. Voirin, V. Lapinte, S. Caillol, J.-J. Robin, Petro-based and bio-based plasticizers: Chemical structures to plasticizing properties, J. Polym. Sci. Part Polym. Chem. 54 (2016) 11-33. https://doi.org/10.1002/pola.27917.

[11] J.-L. Audic, L. Lemiègre, Y.-M. Corre, Thermal and mechanical properties of a polyhydroxyalkanoate plasticized with biobased epoxidized broccoli oil, J. Appl. Polym. Sci. 131 (2014). https://doi.org/10.1002/app.39983.

[12] G. Teng, M.D. Soucek, Epoxidized soybean oil-based ceramer coatings, J. Am. Oil Chem. Soc. 77 (2000) 381-387. https://doi.org/10.1007/s11746-000-0062-0.

[13] K. Ghosal, U. Bhattacharjee, K. Sarkar, Facile green synthesis of bioresorbable polyester from soybean oil and recycled plastic waste for osteochondral tissue regeneration, Eur. Polym. J. 122 (2020) 109338. https://doi.org/10.1016/j.eurpolymj.2019.109338.

[14] G. Acik, Preparation of antimicrobial and biodegradable hybrid soybean oil and poly (L-lactide) based polymer with quaternized ammonium salt, Polym. Degrad. Stab. 181 (2020) 109317. https://doi.org/10.1016/j.polymdegradstab.2020.109317.

[15] G. Acik, Soybean Oil Modified Bio-based Poly(vinyl alcohol)s via Ring-Opening Polymerization, J. Polym. Environ. 27 (2019) 2618-2623. https://doi.org/10.1007/s10924-019-01547-3.

[16] Y. Xia, R. C. Larock, Vegetable oil-based polymeric materials: synthesis, properties, and applications, Green Chem. 12 (2010) 1893-1909. https://doi.org/10.1039/C0GC00264J.

[17] P. Joe, Global Edible Vegetable Oil Market Trends, Biomed. J. Sci. Tech. Res. 2 (2018). https://doi.org/10.26717/BJSTR.2018.02.000680.

[18] A.A. Refaat, Different techniques for the production of biodiesel from waste vegetable oil, Int. J. Environ. Sci. Technol. 7 (2010) 183-213. https://doi.org/10.1007/BF03326130.

[19] F.C. Fernandes, K. Kirwan, D. Lehane, S.R. Coles, Epoxy resin blends and composites from waste vegetable oil, Eur. Polym. J. 89 (2017) 449-460. https://doi.org/10.1016/j.eurpolymj.2017.02.005.

[20] J.M. Fonseca, J.G. Teleken, V. de Cinque Almeida, C. da Silva, Biodiesel from waste frying oils: Methods of production and purification, Energy Convers. Manag. 184 (2019) 205-218. https://doi.org/10.1016/j.enconman.2019.01.061.

[21] K. Warner, B. Vick, L. Kleingartner, R. Isaak, K. Doroff, COMPOSITIONS OF SUNFLOWER, NUSUN (MID-OLEIC SUNFLOWER) AND HIGH-OLEIC SUNFLOWER OILS, (n.d.) 7.

[22] M. Gobin, P. Loulergue, J.-L. Audic, L. Lemiègre, Synthesis and characterisation of bio-based polyester materials from vegetable oil and short to long chain dicarboxylic acids, Ind. Crops Prod. 70 (2015) 213-220. https://doi.org/10.1016/j.indcrop.2015.03.041.

[23] G.S. Sudha, H. Kalita, S. Mohanty, S.K. Nayak, Biobased epoxy blends from epoxidized castor oil: Effect on mechanical, thermal, and morphological properties, Macromol. Res. 25 (2017) 420430. https://doi.org/10.1007/s13233-017-5063-3.

[24] F.C. Fernandes, K. Kirwan, D. Lehane, S.R. Coles, Epoxy resin blends and composites from waste vegetable oil, Eur. Polym. J. 89 (2017) 449-460. https://doi.org/10.1016/j.eurpolymj.2017.02.005.

[25] S. Kumar, S.K. Samal, S. Mohanty, S.K. Nayak, Study of curing kinetics of anhydride cured petroleum-based (DGEBA) epoxy resin and renewable resource based epoxidized soybean oil (ESO) systems catalyzed by 2-methylimidazole, Thermochim. Acta. 654 (2017) 112-120. https://doi.org/10.1016/j.tca.2017.05.016.

\section{ACCEPTED MANUSCRIPT}


[26] F.I. Altuna, L.H. Espósito, R.A. Ruseckaite, P.M. Stefani, Thermal and mechanical properties of anhydride-cured epoxy resins with different contents of biobased epoxidized soybean oil, J. Appl. Polym. Sci. 120 (2011) 789-798. https://doi.org/10.1002/app.33097.

[27] G. Mashouf Roudsari, A.K. Mohanty, M. Misra, Study of the Curing Kinetics of Epoxy Resins with Biobased Hardener and Epoxidized Soybean Oil, ACS Sustain. Chem. Eng. 2 (2014) 2111-2116. https://doi.org/10.1021/sc500176z.

[28] P.T. Mather, X. Luo, I.A. Rousseau, Shape Memory Polymer Research, Annu. Rev. Mater. Res. 39 (2009) 445-471. https://doi.org/10.1146/annurev-matsci-082908-145419.

[29] B. DIETSCH, T. TONG, A review - : Features and benefits of shape memory polymers (SMPs), Rev. - Featur. Benefits Shape Mem. Polym. SMPs. 39 (2007) 3-12.

[30] S. Vyawahare, S. Sitaula, S. Martin, D. Adalian, A. Scherer, Electronic control of elastomeric microfluidic circuits with shape memory actuators, Lab. Chip. 8 (2008) 1530-1535. https://doi.org/10.1039/B804515A.

[31] W.M. Sokolowski, S.C. Tan, Advanced Self-Deployable Structures for Space Applications, J. Spacecr. Rockets. 44 (2007) 750-754. https://doi.org/10.2514/1.22854.

[32] Y.Y.F. Chan Vili, Investigating Smart Textiles Based on Shape Memory Materials, Text. Res. J. 77 (2007) 290-300. https://doi.org/10.1177/0040517507078794.

[33] C. Liu, H. Qin, P. T. Mather, Review of progress in shape-memory polymers, J. Mater. Chem. 17 (2007) 1543-1558. https://doi.org/10.1039/B615954K.

[34] M. Capelot, M.M. Unterlass, F. Tournilhac, L. Leibler, Catalytic Control of the Vitrimer Glass Transition, ACS Macro Lett. 1 (2012) 789-792. https://doi.org/10.1021/mz300239f.

[35] W. Denissen, J. M. Winne, F.E.D. Prez, Vitrimers: permanent organic networks with glass-like fluidity, Chem. Sci. 7 (2016) 30-38. https://doi.org/10.1039/C5SC02223A.

[36] X. Yang, L. Guo, X. Xu, S. Shang, H. Liu, A fully bio-based epoxy vitrimer: Self-healing, tripleshape memory and reprocessing triggered by dynamic covalent bond exchange, Mater. Des. 186 (2020) 108248. https://doi.org/10.1016/j.matdes.2019.108248.

[37] T. Chen, T. Instruments, L. Drive, N. Castle, Characterization of Shape-Memory Polymers by DMA, (n.d.) 8.

[38] F.I. Altuna, C.E. Hoppe, R.J.J. Williams, Shape memory epoxy vitrimers based on DGEBA crosslinked with dicarboxylic acids and their blends with citric acid, RSC Adv. 6 (2016) 8864788655. https://doi.org/10.1039/C6RA18010H.

[39] S. Gharby, H. Harhar, B. Matthäus, Z. Bouzoubaa, Z. Charrouf, The chemical parameters and oxidative resistance to heat treatment of refined and extra virgin Moroccan Picholine olive oil, J. Taibah Univ. Sci. 10 (2016) 100-106. https://doi.org/10.1016/j.jtusci.2015.05.004.

[40] S. Bastida, F.J. Sánchez-Muniz, Thermal Oxidation of Olive Oil, Sunflower Oil and a Mix of Both Oils during Forty Discontinuous Domestic Fryings of Different Foods, Food Sci. Technol. Int. 7 (2001) 15-21. https://doi.org/10.1106/1898-PLW3-6Y6H-8K22.

[41] C.M. Yang, A.A. Grey, M.C. Archer, W.R. Bruce, Rapid quantitation of thermal oxidation products in fats and oils by $1 \mathrm{H}-\mathrm{NMR}$ spectroscopy, Nutr. Cancer. 30 (1998) 64-68. https://doi.org/10.1080/01635589809514642.

[42] I.A. Rousseau, Challenges of shape memory polymers: A review of the progress toward overcoming SMP's limitations, Polym. Eng. Sci. 48 (2008) 2075-2089. https://doi.org/10.1002/pen.21213.

[43] P.J. Flory, Molecular theory of rubber elasticity, Polymer. 20 (1979) 1317-1320. https://doi.org/10.1016/0032-3861(79)90268-4.

[44] J.M. Charlesworth, Effect of crosslink density on molecular relaxations in diepoxide-diamine network polymers. Part 2. The rubbery plateau region, Polym. Eng. Sci. 28 (1988) 230-236. https://doi.org/10.1002/pen.760280406.

[45] H. Nouailhas, C. Aouf, C.L. Guerneve, S. Caillol, B. Boutevin, H. Fulcrand, Synthesis and properties of biobased epoxy resins. part 1. Glycidylation of flavonoids by epichlorohydrin, J. Polym. Sci. Part Polym. Chem. 49 (2011) 2261-2270. https://doi.org/10.1002/pola.24659. 
[46] T. lijima, N. Yoshioka, M. Tomoi, Effect of cross-link density on modification of epoxy resins with reactive acrylic elastomers, Eur. Polym. J. 28 (1992) 573-581. https://doi.org/10.1016/00143057(92)90025-W.

[47] W.W. Graessley, The entanglement concept in polymer rheology, (n.d.) 179.

[48] C. Di Mauro, S. Malburet, A. Genua, A. Graillot, A. Mija, Sustainable Series of New Epoxidized Vegetable Oil-Based Thermosets with Chemical Recycling Properties, Biomacromolecules. 21 (2020) 3923-3935. https://doi.org/10.1021/acs.biomac.0c01059.

[49] C. Menager, N. Guigo, L. Vincent, N. Sbirrazzuoli, Polymerization kinetic pathways of epoxidized linseed oil with aliphatic bio-based dicarboxylic acids, J. Polym. Sci. 58 (2020) 1717-1727. https://doi.org/10.1002/pol.20200118.

[50] Y. Chen, Z. Xi, L. Zhao, New bio-based polymeric thermosets synthesized by ring-opening polymerization of epoxidized soybean oil with a green curing agent, Eur. Polym. J. 84 (2016) 435-447. https://doi.org/10.1016/j.eurpolymj.2016.08.038.

[51] T. Xie, X. Xiao, Y.-T. Cheng, Revealing Triple-Shape Memory Effect by Polymer Bilayers, Macromol. Rapid Commun. 30 (2009) 1823-1827. https://doi.org/10.1002/marc.200900409.

[52] H.T.H. Nguyen, P. Qi, M. Rostagno, A. Feteha, S.A. Miller, The quest for high glass transition temperature bioplastics, J. Mater. Chem. A. 6 (2018) 9298-9331. https://doi.org/10.1039/C8TA00377G.

[53] X. Pan, P. Sengupta, D.C. Webster, High Biobased Content Epoxy-Anhydride Thermosets from Epoxidized Sucrose Esters of Fatty Acids, Biomacromolecules. 12 (2011) 2416-2428. https://doi.org/10.1021/bm200549c.

[54] G. Mashouf Roudsari, A.K. Mohanty, M. Misra, Green Approaches To Engineer Tough Biobased Epoxies: A Review, ACS Sustain. Chem. Eng. 5 (2017) 9528-9541. https://doi.org/10.1021/acssuschemeng.7b01422.

[55] G.D. Smith, D. Bedrov, Relationship between the $\alpha$ - and $\beta$-relaxation processes in amorphous polymers: Insight from atomistic molecular dynamics simulations of 1,4-polybutadiene melts and blends, J. Polym. Sci. Part B Polym. Phys. 45 (2007) 627-643. https://doi.org/10.1002/polb.21064.

[56] B. Qi, Q.X. Zhang, M. Bannister, Y.-W. Mai, Investigation of the mechanical properties of DGEBA-based epoxy resin with nanoclay additives, Compos. Struct. 75 (2006) 514-519. https://doi.org/10.1016/j.compstruct.2006.04.032.

[57] R.J.C. Carbas, E.A.S. Marques, L.F.M. da Silva, A.M. Lopes, Effect of Cure Temperature on the Glass Transition Temperature and Mechanical Properties of Epoxy Adhesives, J. Adhes. 90 (2014) 104-119. https://doi.org/10.1080/00218464.2013.779559.

[58] V.B. Gupta, L.T. Drzal, C.Y.-C. Lee, M.J. Rich, The temperature-dependence of some mechanical properties of a cured epoxy resin system, Polym. Eng. Sci. 25 (1985) 812-823. https://doi.org/10.1002/pen.760251305.

[59] W.B. Song, L.Y. Wang, Z.D. Wang, Synthesis and thermomechanical research of shape memory epoxy systems, Mater. Sci. Eng. A. 529 (2011) 29-34. https://doi.org/10.1016/j.msea.2011.08.049.

[60] F.I. Altuna, C.E. Hoppe, R.J.J. Williams, Shape memory epoxy vitrimers based on DGEBA crosslinked with dicarboxylic acids and their blends with citric acid, RSC Adv. 6 (2016) 8864788655. https://doi.org/10.1039/C6RA18010H.

[61] F.I. Altuna, C.E. Hoppe, R.J.J. Williams, Epoxy vitrimers with a covalently bonded tertiary amine as catalyst of the transesterification reaction, Eur. Polym. J. 113 (2019) 297-304. https://doi.org/10.1016/j.eurpolymj.2019.01.045.

[62] Z. Ma, Y. Wang, J. Zhu, J. Yu, Z. Hu, Bio-based epoxy vitrimers: Reprocessibility, controllable shape memory, and degradability, J. Polym. Sci. Part Polym. Chem. 55 (2017) 1790-1799. https://doi.org/10.1002/pola.28544.

[63] F.I. Altuna, V. Pettarin, R.J.J. Williams, Self-healable polymer networks based on the crosslinking of epoxidised soybean oil by an aqueous citric acid solution, Green Chem. 15 (2013) 3360-3366. https://doi.org/10.1039/C3GC41384E.

\section{ACCEPTED MANUSCRIPT}


[64] F.I. Altuna, C.E. Hoppe, R.J.J. Williams, Shape memory epoxy vitrimers based on DGEBA crosslinked with dicarboxylic acids and their blends with citric acid, RSC Adv. 6 (2016) 8864788655. https://doi.org/10.1039/C6RA18010H. 